\title{
Variation in the interservice intervals of dairy cows in the United Kingdom
}

\author{
J. G. Remnant, ${ }^{1}$ M. J. Green, J. N. Huxley, and C. D. Hudson \\ School of Veterinary Medicine and Science, University of Nottingham, Sutton Bonington Campus, Sutton Bonington, Leicestershire, LE12 5RD, \\ United Kingdom
}

\section{ABSTRACT}

An understanding of the normal estrous-cycle length of the cow is important when managing and monitoring dairy-herd fertility. Although the normal interovulatory interval is widely considered to be $21 \mathrm{~d}$, some studies have found alternative intervals to be more prevalent; previously, most of the variation in interval length was expected to be between cows. The aim of this study was to assess the time between inseminations (interservice interval, ISI) in a large number of dairy cows and to explore possible associations between cow factors and estrous-cycle length. The study used ISI data from 42,252 cows in 159 herds across England and Wales. Univariate analysis of the subset of 114,572 intervals between 15 and $30 \mathrm{~d}$ (a range covering the increased frequency of ISI occurring at the expected time of the first return to estrus) following an insemination revealed a modal ISI of $22 \mathrm{~d}$. Primiparous heifers had a modal ISI of $21 \mathrm{~d}$. Significant differences existed between the distribution of ISI for different yield groups, parity numbers, and the number of inseminations. Multilevel regression modeling was used to evaluate the associations between cow factors and ISI, while accounting for clustering at the herd and cow level. This revealed significant associations between predicted ISI and insemination number, days in milk, lactation 305-d milk yield, and month and year of insemination. Variance partition coefficients indicated that only $1 \%$ of variation in ISI was at the herd level, $12 \%$ at the animal level, and $87 \%$ at the insemination level, indicating that cycle length varies substantially more between cycles within a cow than between cows or herds. These findings suggest the normal range of ISI for modern UK dairy cows is longer than expected and cycle length has a large amount of unexplained variation within individual animals over time.

Key words: interservice interval, interovulatory interval, estrous cycle

Received May 15, 2014.

Accepted November 8, 2014.

${ }^{1}$ Corresponding author: john.remnant@nottingham.ac.uk

\section{INTRODUCTION}

Good reproductive performance is an essential part of any successful dairy enterprise, and heat detection is an important part of this in herds using artificial insemination. It is commonly accepted that the estrous cycle of domestic cattle (Bos taurus) is approximately $21 \mathrm{~d}$ long, with a normal range of between 18 and $24 \mathrm{~d}$ (Hartigan, 2004; Forde et al., 2011). A more accurate knowledge of normal cycle length may contribute to improved heat detection. It has been demonstrated that variation in estrous-cycle length occurs primarily between cows rather than within cows (Olds and Seath, 1951). The number of follicular waves in the estrous cycle of a cow affects the interovulatory interval (IOI; Ginther et al., 1989), and the number of follicular waves in a cycle is also repeatable between cycles within a cow (Jaiswal et al., 2009). Some studies have shown improved fertility in cows following 2-wave cycles as opposed to 3-wave cycles (Townson et al., 2002). Explaining the between-cow variation in IOI may uncover mechanisms to improve fertility.

The expected normal range of IOI is used to calculate a variety of fertility parameters employed by veterinarians, farmers, and other professionals to monitor dairy-herd heat detection (Hudson et al., 2012b). These include first-service submission rate (the proportion of cows that are inseminated within $24 \mathrm{~d}$ of the end of the voluntary waiting period), return-to-service submission rate (the proportion of cows reinseminated 18 to $24 \mathrm{~d}$ after an unsuccessful insemination), and analysis of interservice interval (ISI) profiles. Expected cycle length could also affect the interpretation of commonly used indices for monitoring overall reproductive performance, such as the proportion of eligible cows becoming pregnant every $21 \mathrm{~d}$ (21-d pregnancy risk or fertility efficiency, common in year-round calving herds) or the proportion of cows pregnant within the first 21 or $42 \mathrm{~d}$ of the breeding season (in seasonally calving enterprises). As well as allowing useful monitoring of heat detection, awareness of the normal ISI can directly help improve heat detection by allowing more accurate prediction of the next heat. A reliable figure is also useful in research, for example for constructing 
simulation models of reproduction, with many authors using a fixed cycle length of $21 \mathrm{~d}$ in their models (BrunLafleur et al., 2013).

Globally, milk yield has been increasing over time, and until recently, dairy-herd fertility had been declining. Delayed return to normal ovarian cyclicity, reduced heat expression, and poor conception rates are commonly implicated in this trend (Dobson et al., 2007; Walsh et al., 2011). The effect of increased level of production in reducing the time and intensity of estrus expression has been well documented (Lopez et al., 2004); an association between increasing milk yield and an increase in the incidence of abnormal ovarian cycles (particularly prolonged luteal phases) has also been shown (Kafi et al., 2012). It is plausible that production may have an effect on ISI length.

The aim of this study was to assess the ISI in a large number of dairy cows, to explore the variability in estrous-cycle length and to identify associations between cow factors and cycle length. A more accurate understanding of the normal ISI of a cow would enable this knowledge to be used when interpreting herd production parameters. Understanding the variability of estrous-cycle length will allow identification of potential mechanisms regulating this process.

\section{MATERIALS AND METHODS}

\section{Data Collection and Organization}

Herd-management data were collected as part of a larger project (Hudson et al., 2010, 2012a). The commonly used ISI based measures of estrus-detection efficiency have been applied to this data set in a separate study (Remnant et al., 2014). Anonymized herd databases were requested from 20 veterinary surgeons across England and Wales with an acknowledged interest in dairy-herd health-management data analysis. Data came from a variety of sources, including on-farm recording software, veterinary practice bureau-recording services, and the records of national milk-recording organizations. Although not a probabilistic sampling method, this convenience sample was considered appropriate because high-quality data were essential for the analysis.

The initial data consisted of databases from 468 dairy herds. The data sets were converted to a standard format for restructuring and initial analysis. Data quality was assessed at the herd-year level over $8 \mathrm{yr}$, with only calendar years considered acceptable included for each herd. Measures of data quality included identification of herd data sets with random errors (such as calving events recorded without a corresponding insemination event) and systematic errors (such as underrecording of unsuccessful insemination events). Further detail is given by Hudson et al. (2012a). The resulting data were from the years 2000 to 2008, originated from 167 herds, and included 449,471 inseminations from 67,926 cows. Mean 305-d milk yield, calving index, culling rate, and average herd size (estimated by multiplying the number of calving events in a year by the calving index divided by 365$)$ were calculated for each herd for each calendar year.

The data were structured with an individual ISI (the number of days between subsequent inseminations in the same cow, in the same lactation) as a line of data. For each interval, the cow and herd identity were recorded, along with the 305-d adjusted milk yield, start (calving) date, and parity of the lactation in which the ISI occurred. The date, DIM, and insemination number of the insemination ending the interval were also recorded. Lactations with milk yields outside the range 2,500 to $15,000 \mathrm{~L}$ and ISI ending at more than 365 DIM were excluded, because these were likely to represent outliers and recording errors.

Data restructuring was carried out in Microsoft Access 2010 (Microsoft Corporation, Redmond, WA).

\section{Descriptive Analysis}

A frequency distribution of ISI up to $100 \mathrm{~d}$ was plotted. For initial univariate analysis, a subset of intervals between 15 and $30 \mathrm{~d}$ was used. The initial distribution demonstrated a clear peak at 15 to $30 \mathrm{~d}$, and this is a range thought likely to contain the first return to estrus following an insemination, without including subsequent cycles (occurring at extended intervals as a result of failed estrus detection or resynchronization protocols). Herds contributing less than 100 ISI within this range were excluded, leaving a sample consisting of 114,573 ISI from 42,252 cows in 159 herds. Summary herd-level statistics for herd-years included in the analysis are shown in Table 1 . The distribution of ISI within this sample was assessed using a frequency plot. Bar charts were used to compare the distribution of ISI across different parities (grouped as 1, 2, 3, or $4+$ ), insemination numbers (grouped as $2,3,4$, or $5+$ according to the number of the insemination ending the interval), and lactation 305-d adjusted milk yield grouped as $<7,000 \mathrm{~L}, 7,000$ to $10,000 \mathrm{~L}$, and $\geq 10,000$ $\mathrm{L}$, based on the approximate bottom quartile $(<7,021$ $\mathrm{L})$, median half, and top quartile $(>9,934 \mathrm{~L})$ of all insemination-level 305-d lactation yields]. First-lactation heifers were excluded from the univariate yield category plot. Differences between groups were tested with 
Table 1. Summary statistics for 1,275 herd-years from 159 herds included in the analysis of interservice intervals (following data-quality screening)

\begin{tabular}{lcccc}
\hline Item & $\begin{array}{c}\text { 305-d milk } \\
\text { yield (kg) }\end{array}$ & $\begin{array}{c}\text { Calving } \\
\text { index (d) }\end{array}$ & $\begin{array}{c}\text { Cull } \\
\text { rate (\%) }\end{array}$ & $\begin{array}{c}\text { Herd } \\
\text { size }\end{array}$ \\
\hline Mean & 7,437 & 415 & 25 & 190 \\
Median & 7,534 & 412 & 23 & 167 \\
Upper quartile & 8,344 & 427 & 30 & 222 \\
Lower quartile & 6,735 & 399 & 17 & 116 \\
\hline
\end{tabular}

a Kruskal-Wallis rank sum test, with $P$-values $\leq 0.05$ considered significant.

Univariate data analysis was carried out in Microsoft Excel 2010 (Microsoft Corporation) and R version 3.0.2 (R Core Team, 2013).

\section{Statistical Modeling}

A regression model to predict ISI was fitted using the subset of ISI at 15 to $30 \mathrm{~d}$ (as described earlier). A 3-level random effects structure was used to account for potential clustering of ISI at the animal and herd level, with an individual interval as the lowest level unit of data. The model was built by forward selection. Explanatory variables were added to the model sequentially and coefficients and standard errors of coefficients estimated. For continuous predictor variables, polynomial functions up to degree 3 were tested, as were terms representing biologically plausible firstorder interactions. Variables were retained in the model where the estimated coefficient was greater than twice the standard error (such that the $95 \%$ confidence interval for the estimate did not include zero); all rejected variables were reoffered to the final model and retained if they now met these criteria. In the case of categorical explanatory variables, all categories were retained in the model if one or more of the categories met the criteria. The model took the conventional form:

$$
\begin{gathered}
\operatorname{ISI}_{i j k}=\beta_{0 i j k}+\boldsymbol{\beta}_{1} \mathbf{x}_{1 i j k}, \\
\beta_{0 i j k}=\beta_{0}+v_{0 k}+u_{0 j k}+e_{0 i j k},
\end{gathered}
$$

$$
\begin{aligned}
& \nu_{0 k} \sim N\left(0, \sigma_{\nu 0}^{2}\right), \\
& u_{0 j k} \sim N\left(0, \sigma_{u 0}^{2}\right), \\
& e_{0 i j k} \sim N\left(0, \sigma_{e 0}^{2}\right),
\end{aligned}
$$

where $\operatorname{ISI}_{i j k}$ is the $i$ th ISI, for the $j$ th cow in the $k$ th herd; $\beta_{0 i j k}$ is the model intercept, composed of $\beta_{0}$ the overall intercept, $v_{0 k}$ the herd-level residual for the $k$ th herd, $u_{0 j k}$ the cow-level residual for the $j$ th animal, and $e_{0 i j k}$ the insemination-level residual for the $i$ th insemination; residuals were assumed to be normally distributed $(\sim \mathrm{N})$ with mean 0 and variance $\sigma_{v 0}^{2}, \sigma_{u 0}^{2}$, and $\sigma_{e 0}^{2}$, respectively; $\mathbf{x}_{1 i j k}$ represents the matrix of predictor variables for the $i$ th ISI in the $j$ th cow in the $k$ th herd; and $\boldsymbol{\beta}_{1}$ the corresponding matrix of coefficients. All potential predictor variables used in model building are shown in Table 2. To quantify the amount of variability in ISI at each level (variation in ISI occurring between inseminations within the same cow; variation in ISI occurring between cows within a herd; variation in average ISI between herds), variance partition coefficients were calculated for each level of the model by dividing the variance of the residuals at each level by the total variance. The final model was also compared with a null model consisting only of herd-level, animal-level, and insemination-level random effects, to calculate the percentage of the initial variance at each level, which was explained by the predictor variables.

To evaluate model fit, a histogram and a normal probability plot of the insemination-level residuals were generated to check for normality; the standardized insemination-level residuals were plotted against the

Table 2. Potential predictor variables used for building a multilevel regression model of interservice interval (ISI)

\begin{tabular}{ll}
\hline Variable & Variable type \\
\hline $305-\mathrm{d}$ milk yield $(\times 1,000 \mathrm{~kg})$ & Continuous (centered around population mean) \\
Year in which the lactation began & Categorical (2000, 2001,.., 2008) \\
Calendar month in which the ISI ends & Categorical (January, February,.., December) \\
Lactation number & Categorical (parity 1,2,3,4+) \\
$\begin{array}{l}\text { DIM at the end of the ISI } \\
\text { Number of inseminations in the lactation, including the insemination } \\
\text { ending the ISI }\end{array}$ & Continuous \\
\hline
\end{tabular}


ranked observed values to assess homoscedasticity; and the predicted values were plotted against the observed values. Model parameters were reestimated following removal of outlying points identified using the diagnostic plots to assess their effect on the parameter estimates. An alternative model using a t-distribution outcome was also explored to reflect the apparently heavy-tailed distribution of the ISI. This was compared with the initial (normal outcome) model to assess differences in parameter estimates.

To illustrate model results, predictions were made for example scenarios, by fixing all explanatory variables at their mean or reference category and then calculating the predicted outcome across a range of values for a single explanatory variable at a time, with predictions illustrated graphically (Archer et al., 2013).

The main regression analysis was carried out using MLwiN version 2.10 (Rasbash et al., 2009) using iterative generalized least squares for parameter estimation, and estimation for the alternate model with a t-distributed outcome was performed using Markov chain Monte Carlo sampling in WinBUGS version 1.4 (Lunn et al., 2000).

\section{RESULTS}

\section{Descriptive Analysis}

Figure 1 shows the distribution of all the ISI from 1 to $100 \mathrm{~d}$; a clear peak in the frequency of inseminations occurred at an interval of around $3 \mathrm{wk}$, with a smaller increase around $6 \mathrm{wk}$. The distribution of intervals by day within a 15- to $30-\mathrm{d}$ window is shown in Figure 2A; the modal ISI across the full data set was $22 \mathrm{~d}$. The accepted normal range of 18 to 24 d encompassed $59 \%$ of ISI in the 15 to $30 \mathrm{~d}$ window. The central $90 \%$ of the ISI fell within the range 18 to 28 . Figure $2 \mathrm{~B}$ shows the distribution of intervals for different yield groups. The modal interval was $22 \mathrm{~d}$ for all yield groups; however, there was a clear trend for longer ISI in lactations with higher $305-\mathrm{d}$ milk yield $(P<0.001)$. Figure $2 \mathrm{C}$ shows the distribution for different parity groups. It appeared that ISI increased with parity $(P<0.001)$; all groups had a modal ISI of $22 \mathrm{~d}$, with the exception of firstlactation heifers, which had a mode of $21 \mathrm{~d}$. Figure 2D shows the distribution of ISI by insemination number, the mode remained $22 \mathrm{~d}$ for all groups, and a trend existed for longer ISI in later inseminations $(P=0.023)$.

\section{Statistical Modeling}

The variance partition coefficients for the final model indicated that most of the unexplained variation in ISI was at the individual insemination level. Only $1 \%$ of the variation of ISI was from differences between herds; $12 \%$ was explained by differences in ISI between animals within a herd. The remaining $87 \%$ of variation was at the level of the individual insemination; that is between ISI within an animal. When comparing the final model to the null model, the explanatory variables included accounted for $18 \%$ of the null-model herd-level variance, $6 \%$ of the animal-level variance, and $1 \%$ of the insemination-level variance.

The coefficients and their standard errors for the model are given in Table 3. Model fit was considered good following the assessments described above (Figure 3 ). Parameter estimates did not substantially change with outlying points removed or when modeling the outcome as a t-distribution; as a result, only the results from the conventional model are presented. Interservice interval and increasing parity had a positive association, with cows in lactation number 4 or more predicted to have ISI around half a day longer than first-lactation heifers. The positive association between milk yield and ISI observed in the descriptive analysis was also demonstrated in the multivariable model, although the magnitude of the effect was very small, with a predicted increase of $0.024 \mathrm{~d}$ for every $1,000 \mathrm{~L}$ of milk, when parity was accounted for. The ISI appeared to vary seasonally, with a shorter ISI in the months June through to November, with predicted ISI around one fifth of a day shorter in July, August, and September when compared with January. Year was also associated; the ISI lengthened over the period the data were gathered, with an increase in ISI of approximately 0.26 of a day in 2008 compared with the year 2000. A quadratic relationship existed between DIM and ISI, with predicted ISI increasing with DIM up to approximately

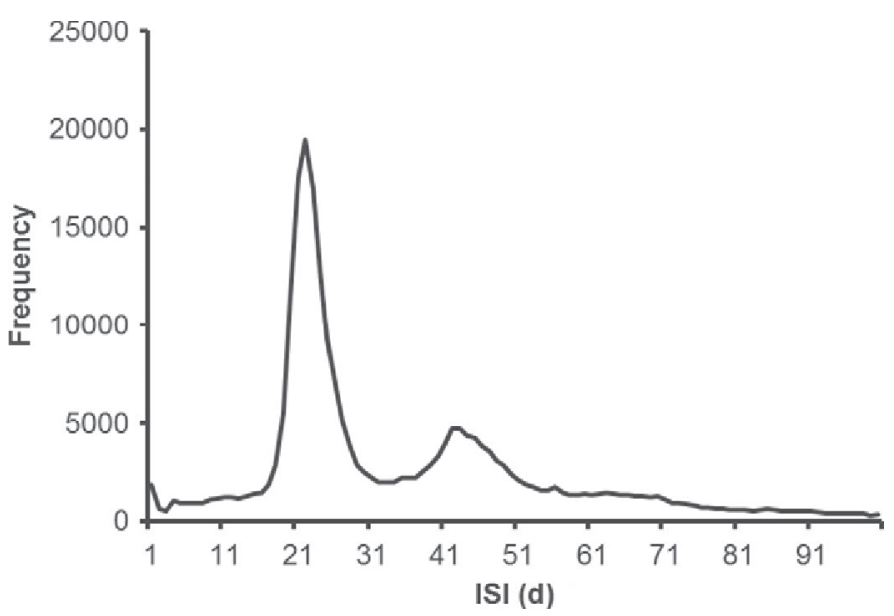

Figure 1. Frequency distribution of interservice intervals (ISI) between 1 and $100 \mathrm{~d}$, recorded between the years 2000 and 2008 in 167 UK dairy herds. 

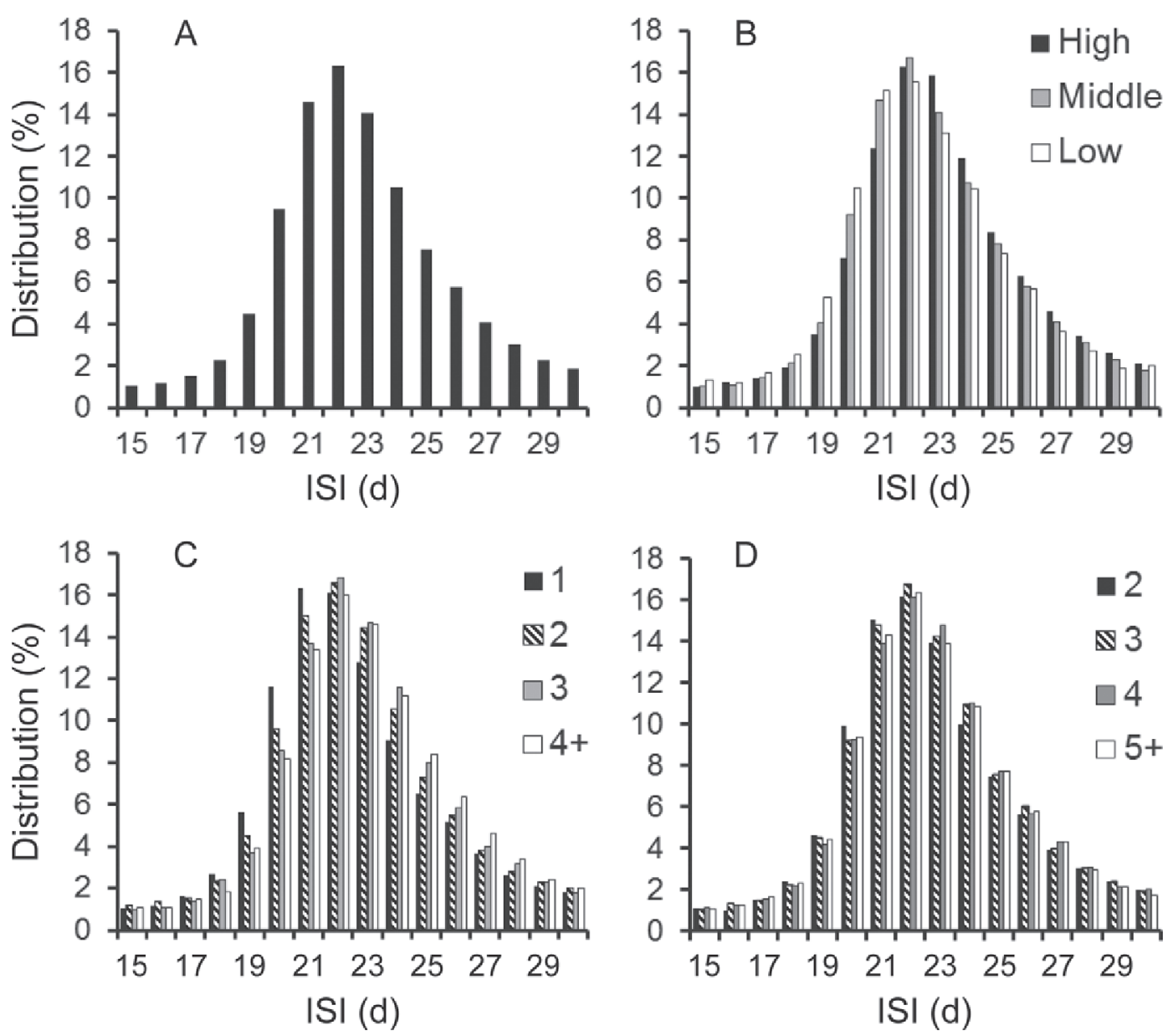

Figure 2. Bar charts showing the distribution of 114,573 interservice intervals (ISI) between 15 and $30 \mathrm{~d}$ within different subgroups of 42,252 cows from 159 UK dairy herds. (A) All ISI between 15 and $30 \mathrm{~d}$; (B) 305-d lactation milk-yield groups: low (<7,000 L), middle (7,000 to 10,000 L), and high yielding (>10,000 L) in multiparous cows; (C) parity groups. (D) groups by insemination number (within a cow, within a lactation).

250 DIM and then decreasing slightly in later lactation. The predicted ISI for the average cow increased from approximately 21 to more than 23 d between 30 and 250 DIM; this association is illustrated in Figure 4. Another large effect size in the model was the association between ISI and insemination number, with the predicted interval preceding a fifth insemination or later in a lactation approximately $0.8 \mathrm{~d}$ shorter than the interval between a first and second insemination; this effect is illustrated in Figure 5.

\section{DISCUSSION}

In the current study most of the variation in ISI occurs at the individual ISI level within cows, which along with the fact that the final model only explained $1 \%$ of the insemination-level variance in the null model, implies that a variable or variables not included in the model that applies at the insemination level has a major effect on ISI. Previously it had been documented that IOI is consistent within a cow, with most variation occurring between cows (Jaiswal et al., 2009). Because the current study used ISI as a proxy for IOI, embryonic death is one possible explanation for this. Longer intervals may be a result of successful conception and embryonic death delaying the second estrus (Diskin et al., 2011). This could also explain the trend for extended intervals in high-milk-producing cows, with these cows expected to have a higher incidence of embryonic death (Sartori et al., 2002). The distribution of all the ISI between 15 and $30 \mathrm{~d}$ is slightly asymmetrical, with a slight positive skew, which could possibly be caused by embryonic death (Figure 2A). However, the shape of the distribution of ISI from the high-yield group is very similar to that of the low-yielding group (see Figure 2B), although centered on a higher interval. An increase in the amount of embryonic death would be expected to increase the number of extended ISI (because of the extended intervals of those cows where embryonic death occurs) but would not influence the number of shorter ISI. Thus, if 


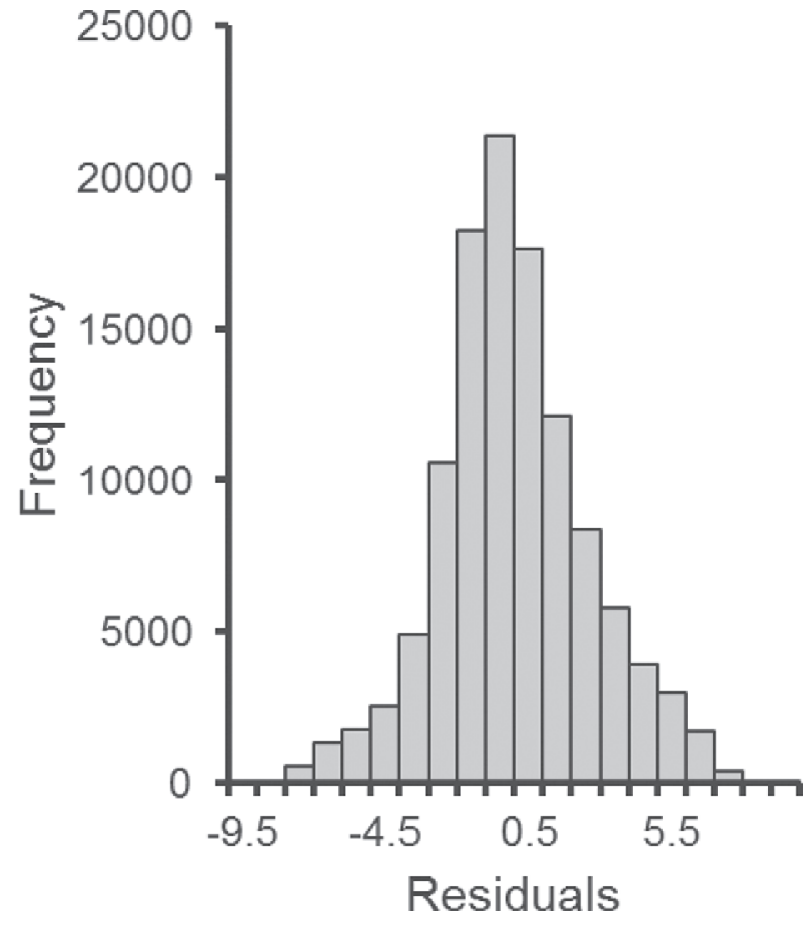

Figure 3. Histogram of 114,573 insemination-level residuals for a multilevel regression model with the outcome interservice interval based on data from 42,252 cows in 159 UK dairy herds between the years 2000 and 2008 .

embryonic death accounted for the increase in ISI with increased yield, the distribution of ISI may be expected to be more right-skewed in high-milk-producing cows.

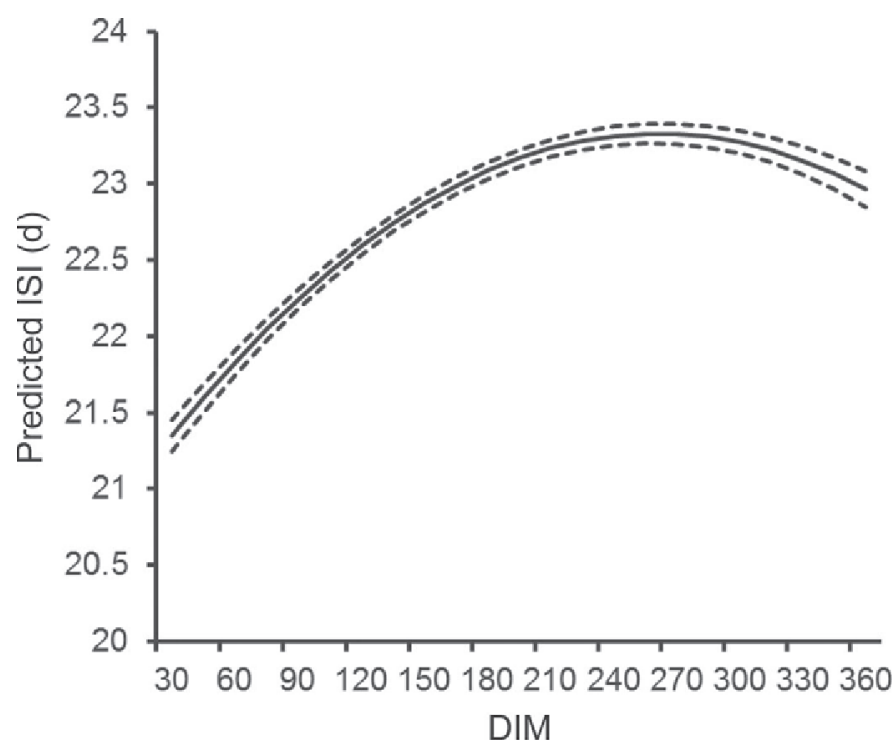

Figure 4. Predicted interservice interval (ISI) from a multilevel regression model based on data from 42,252 cows in 159 UK dairy herds across a range of DIM; the dashed lines show the $95 \%$ confidence interval for the prediction.
Table 3. Parameter estimates for a multilevel regression model predicting interservice interval (ISI) based on data from 42,252 cows in 159 UK dairy herds

\begin{tabular}{|c|c|c|}
\hline Model term & Coefficient & $\mathrm{SE}$ \\
\hline ISI & Outcome & \\
\hline Intercept & 20.764 & 0.087 \\
\hline \multicolumn{3}{|l|}{ Fixed effects } \\
\hline $305-\mathrm{d}$ milk yield $(\times 1,000 \mathrm{~kg})$ & 0.024 & 0.006 \\
\hline Yr 2000 & Reference & \\
\hline Yr 2001 & 0.088 & 0.065 \\
\hline Yr 2002 & 0.126 & 0.061 \\
\hline Yr 2003 & 0.158 & 0.059 \\
\hline Yr 2004 & 0.154 & 0.058 \\
\hline Yr 2005 & 0.142 & 0.057 \\
\hline Yr 2006 & 0.157 & 0.057 \\
\hline Yr 2007 & 0.235 & 0.056 \\
\hline Yr 2008 & 0.263 & 0.056 \\
\hline Mo 1 & Reference & \\
\hline Mo 2 & 0.027 & 0.038 \\
\hline Mo 3 & 0.02 & 0.039 \\
\hline Mo 4 & 0.038 & 0.041 \\
\hline Mo 5 & -0.071 & 0.041 \\
\hline Mo 6 & -0.195 & 0.042 \\
\hline Mo 7 & -0.203 & 0.042 \\
\hline Mo 8 & -0.184 & 0.043 \\
\hline Мо 9 & -0.219 & 0.043 \\
\hline Mo 10 & -0.162 & 0.041 \\
\hline Mo 11 & -0.111 & 0.04 \\
\hline Mo 12 & 0 & 0.038 \\
\hline Parity 1 & Reference & \\
\hline Parity 2 & 0.227 & 0.026 \\
\hline Parity 3 & 0.408 & 0.029 \\
\hline Parity 4 & 0.519 & 0.026 \\
\hline DIM & 0.019 & 0.001 \\
\hline $\mathrm{DIM}^{2}$ & $-3.7 \times 10^{-5}$ & $1.7 \times 10^{-6}$ \\
\hline Insemination number 2 & Reference & \\
\hline Insemination number 3 & -0.334 & 0.025 \\
\hline Insemination number 4 & -0.596 & 0.032 \\
\hline Insemination number 5 & -0.823 & 0.037 \\
\hline \multicolumn{3}{|l|}{ Random effects } \\
\hline Herd-level variance & 0.089 & 0.012 \\
\hline Animal-level variance & 1.057 & 0.029 \\
\hline Insemination-level variance & 7.562 & 0.038 \\
\hline
\end{tabular}

There are possible explanations other than late embryonic death for the variable and increased ISI. Lamming and Darwash (1998) analyzed progesterone profiles of 1,682 dairy cows and found $6.35 \%$ of second or subsequent estrus events had a persistent corpus luteum (defined as a period of elevated progesterone lasting more than $19 \mathrm{~d}$ ), $12.9 \%$ had delayed ovulation (defined as periods of reduced progesterone lasting more than $12 \mathrm{~d}$ ), and $9.92 \%$ late embryo mortality (defined as elevated progesterone lasting for $19 \mathrm{~d}$ following insemination and then declining). Interestingly, the $31.72 \%$ of cows exhibiting at least one atypical cycle in this study had significantly poorer fertility than those cows with normal cyclicity. Another possible explanation for the variation in cycle length is changes to the follicular wave pattern of cattle; 3 -wave cycles have been shown on average to be longer than 2-wave cycles, but reports are contradictory as to which is more common (Ad- 


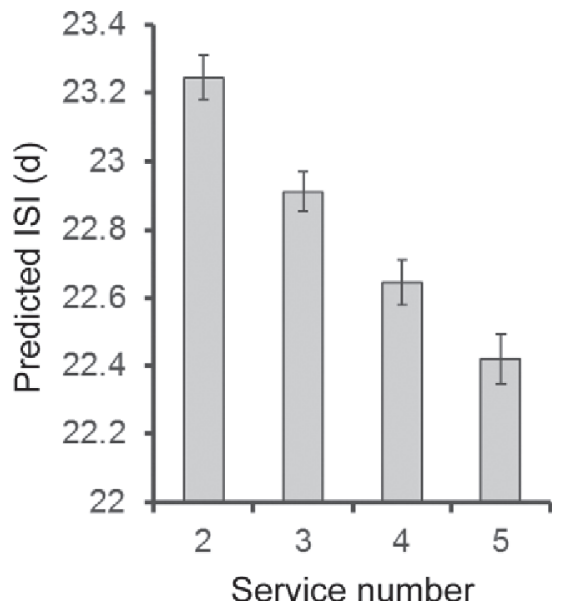

Figure 5. Predicted interservice interval (ISI) by inseminationnumber category (number of inseminations occurring within the same cow within a lactation, service number) from a multilevel regression model based on data from 42,252 cows in 159 UK dairy herds; error bars represent $95 \%$ confidence intervals for each prediction.

ams et al., 2008). Previous work has shown that the follicular wave pattern is repeatable for an individual cow (Jaiswal et al., 2009). The unexplained variation in ISI within a cow indicates that cycle length (and therefore potentially follicular-wave number) may be less consistent than previously thought. The findings in this study indicate that an unexplained and inherent variability of cycle length exists for an individual cow, which clearly warrants further studies to evaluate the underlying physiological mechanisms.

In the current study it is likely that not all recorded insemination events will represent true estrus events, and that not all true estrus events will result in a recorded insemination. In a data set this size, this effect should only introduce random background "noise" with no systematic increase or decrease in ISI. This is supported by the presence of a period of increased frequency of reinseminations (ISI) around 3 wk after a previous insemination (15-30 d, as shown in Figure 1). Based on physiology, these intervals would be expected to represent correctly identified estrus events. Using ISI as a proxy for IOI (as opposed to using insemination data as a proxy for ovulation date) also means that any deliberate difference between ovulation and timing of service is likely to be applied consistently to both inseminations bounding the interval. This means that the ISI should correspond to the IOI even if the insemination time does not coincide with ovulation.

In this sample of UK dairy cows, the modal ISI was longer than the expected normal (IOI) of $21 \mathrm{~d}$ (Hartigan, 2004; Forde et al., 2011). That this represents a true reflection of IOI is further supported by the find- ings of several recent physiological studies revealing an IOI of greater than $21 \mathrm{~d}$ (Bleach et al., 2004; Sartori et al., 2004; Wolfenson et al., 2004). The current study indicates that the discrepancy between the average IOI observed in these physiological studies on smaller numbers of animals and the commonly accepted average IOI of $21 \mathrm{~d}$ is widespread among UK dairy cows. This brings into question the continued use of the 21-d normal interval, particularly given that a similar finding from ISI data was reported as long ago as the 1950s by Olds and Seath (1951) following analysis of records from 278 cows on a research farm in Kentucky. Some of the early research on ovarian cycles in cattle was conducted on nulliparous heifers (Hammond, 1927, cited in Chapman and Casida, 1935; Werner et al., 1938; Joubert, 1954). In the current study, primiparous heifers appear to have shorter intervals than higherparity cows, and it is possible that this trend would extend to nulliparous heifers. This is further supported by Sartori et al. (2004), who found a shorter IOI in heifers compared with cows and suggest that findings from studies carried out on the estrous cycle of heifers cannot be directly applied to later-parity dairy cows. Previous studies have found an effect of breed; Joubert (1954) reported a bimodal distribution of IOI, attributing a second peak of IOI at $22 \mathrm{~d}$ to longer cycles of Friesian cows. Other studies have observed similarly longer cycles in Holstein-Friesian type animals (Britt, 1995). With a trend away from traditional breeds toward Friesian and Holstein genetics since the 1950s, it seems possible that this may have resulted in IOI being longer than those demonstrated in older studies carried out on traditional breeds. Pragmatically, it is also possible that $21 \mathrm{~d}$ has remained the accepted normal interval because a 3 -wk cycle is easier to discuss than a 3-wk-and-1-d cycle. Although the difference between the commonly accepted IOI of $21 \mathrm{~d}$ and the apparently more common interval of $22 \mathrm{~d}$ is only one day, the normal range of 18 to $24 \mathrm{~d}$ appears inappropriate. A better estimation of the normal range maybe the 18 - to 28 -d range incorporating $90 \%$ of the ISI between 15 and 30 in this study. In some instances it may be appropriate to use a different normal range for heifers than for multiparous cows.

As well as the strong association of ISI with parity, many other associations became apparent in the current study. The negative association of insemination number with ISI was relatively large. Days in milk is already accounted for in the model and so this effect is separate to any effect of increasing insemination numbers corresponding to increasing DIM. This is a relatively large and consistent effect (illustrated in Figure 5) and yet is hard to explain physiologically. This is an area that 
warrants further investigation, to establish the mechanism that appears to be shortening the ISI of cows that have received multiple inseminations. The association between milk yield and ISI appears relatively small in magnitude once confounding factors are accounted for. Results from the multivariate regression analysis suggest that the apparent relationship illustrated in Figure 2B was mostly explained by the association with parity, despite primiparous animals being excluded from this figure. Although lactation 305-d milk yield exhibited a small effect size, DIM had a much larger effect. The predicted difference in ISI between a high $(15,000 \mathrm{~kg})$ and low $(2,500 \mathrm{~kg})$ yielding cow was $0.3 \mathrm{~d}$, whereas the predicted ISI varied by around $2 \mathrm{~d}$ over the observed range of DIM. As shown in Figure 4, ISI appears to vary throughout lactation, gradually increasing up to approximately $250 \mathrm{~d}$ in milk. In the current study only lactation yield data were available for the sample analyzed, and it has been demonstrated that the effect of production on fertility is often related to the extent of negative energy balance in early lactation and not the total milk produced (Wathes et al., 2007). Days in milk may better represent any effect of milk yield at the time of the insemination than lactation 305-d milk yield in this model; however, the largest effect of DIM at $250 \mathrm{~d}$ does not coincide with the expected peak in production. In the future, similar analyses using the nearest testday milk yield to the insemination may represent this effect better. A small but significant seasonal pattern of ISI existed, with a trend for shorter intervals in the summer months. There is also a trend for ISI extending through time, with longer intervals found in lactations starting in 2008 than those starting in 2000. This trend is harder to explain but may represent a longer-term change to ISI in dairy cows, perhaps related to selective breeding and changes in genetics.

\section{CONCLUSIONS}

In a large sample of UK dairy herds, most variation in ISI length occurred between cycles within cows (87\%) compared with the variation between cows within a herd (12\%). The most common interval between inseminations was $22 \mathrm{~d}$ rather than the accepted $21-\mathrm{d}$ normal interval, with a range of 18 to $28 \mathrm{~d}$ incorporating $90 \%$ of ISI. Various factors have an association with ISI and would be expected to have a similar association with IOI, including parity, DIM, and insemination number. A small association existed with production as measured by lactation 305-d yield. Further work is needed to elucidate the physiological mechanisms behind these associations and behind the unexplained within-cow variation in cycle length.

\section{REFERENCES}

Adams, G. P., R. Jaiswal, J. Singh, and P. Malhi. 2008. Progress in understanding ovarian follicular dynamics in cattle. Theriogenology 69:72-80.

Archer, S. C., F. Mc Coy, W. Wapenaar, and M. J. Green. 2013. Association between somatic cell count early in the first lactation and the longevity of Irish dairy cows. J. Dairy Sci. 96:2939-2950.

Bleach, E. C. L., R. G. Glencross, and P. G. Knight. 2004. Association between ovarian follicle development and pregnancy rates in dairy cows undergoing spontaneous oestrous cycles. Reproduction 127:621-629.

Britt, J. H. 1995. The relationship between postpartum estrous cycles, estrus cycle length, and early embryonic death. Cattle Pract. $3: 85-88$.

Brun-Lafleur, L., E. Cutullic, P. Faverdin, L. Delaby, and C. Disenhaus. 2013. An individual reproduction model sensitive to milk yield and body condition in Holstein dairy cows. Animal 7:13321343.

Chapman, A., and L. Casida. 1935. Factors associated with breeding efficiency in dairy cattle. J. Anim. Sci. 1935:57-62.

Diskin, M. G., M. H. Parr, and D. G. Morris. 2011. Embryo death in cattle: An update. Reprod. Fertil. Dev. 24:244-251.

Dobson, H., R. F. Smith, M. D. Royal, C. H. Knight, and I. M. Sheldon. 2007. The high-producing dairy cow and its reproductive performance. Reprod. Domest. Anim. 42:17-23.

Forde, N., M. E. Beltman, P. Lonergan, M. Diskin, J. F. Roche, and M. A. Crowe. 2011. Oestrous cycles in Bos taurus cattle. Anim. Reprod. Sci. 124:163-169.

Ginther, O. J., L. Knopf, and J. P. Kastelic. 1989. Temporal associations among ovarian events in cattle during oestrous cycles with two and three follicular waves. J. Reprod. Fertil. 87:223-230.

Hammond, J. 1927. The Physiology of Reproduction in the Cow. Cambridge University Press, Cambridge, UK.

Hartigan, P. J. 2004. Reproductive physiology in cattle. Pages 471-505 in Bovine Medicine: Diseases and Husbandry of Cattle. 2nd ed. A. H. Andrews, R. W. Blowey, H. Boyd, and R. G. Eddy, ed. Blackwell Science Ltd., Oxford, UK.

Hudson, C. D., A. J. Bradley, J. E. Breen, and M. J. Green. 2012a. Associations between udder health and reproductive performance in United Kingdom dairy cows. J. Dairy Sci. 95:3683-3697.

Hudson, C. D., J. E. Breen, A. J. Bradley, and M. J. Green. 2010. Fertility in UK dairy herds: Preliminary findings of a large-scale study. Cattle Pract. 18:89-94.

Hudson, C. D., M. Kerby, J. Statham, and W. Wapenaar. 2012b. Managing herd reproduction. Pages 73-116 in Dairy Herd Health. M. Green, ed. CABI, Wallingford, UK.

Jaiswal, R. S., J. Singh, L. Marshall, and G. P. Adams. 2009. Repeatability of 2-wave and 3-wave patterns of ovarian follicular development during the bovine estrous cycle. Theriogenology 72:81-90.

Joubert, D. M. 1954. The influence of high and low nutritional planes on the oestrous cycle and conception rate of heifers. J. Agric. Sci. $45: 164-172$.

Kafi, M., A. Mirzaei, A. Tamadon, and M. Saeb. 2012. Factors affecting the occurrence of postpartum prolonged luteal activity in clinically healthy high-producing dairy cows. Theriogenology $77: 421-429$.

Lamming, G. E., and A. O. Darwash. 1998. The use of milk progesterone profiles to characterise components of subfertility in milked dairy cows. Anim. Reprod. Sci. 52:175-190.

Lopez, H., L. D. Satter, and M. C. Wiltbank. 2004. Relationship between level of milk production and estrous behavior of lactating dairy cows. Anim. Reprod. Sci. 81:209-223.

Lunn, D., A. Thomas, N. Best, and D. Spiegelhalter. 2000. WinBUGS-A Bayesian modelling framework: Concepts, structure, and extensibility. Stat. Comput. 10:325-337.

Olds, D., and D. M. Seath. 1951. Repeatability of the estrous cycle length in dairy cattle. J. Dairy Sci. 34:626-632.

R Core Team. 2013. R: A Language and Environment for Statistical Computing. R Foundation for Statistical Computing, Vienna, Austria. 
Rasbash, J., C. Charlton, W. J. Browne, M. Healy, and B. Cameron. 2009. MLwiN Version 2.1. Centre for Multilevel Modelling, University of Bristol, Bristol, UK.

Remnant, J. G., J. N. Huxley, and C. D. Hudson. 2014. A fresh look at inter-service intervals in UK dairy herds. Cattle Pract. In press. http://www.bcva.eu/bcva/education/documents/fresh-look-interservice-intervals-uk-dairy-herds.

Sartori, R., J. M. Haughian, R. D. Shaver, G. J. M. Rosa, and M. C. Wiltbank. 2004. Comparison of ovarian function and circulating steroids in estrous cycles of Holstein heifers and lactating cows. J. Dairy Sci. 87:905-920.

Sartori, R., R. Sartor-Bergfelt, S. A. Mertens, J. N. Guenther, J. J. Parrish, and M. C. Wiltbank. 2002. Fertilization and early embryonic development in heifers and lactating cows in summer and lactating and dry cows in winter. J. Dairy Sci. 85:2803-2812.

Townson, D. H., P. C. Tsang, W. R. Butler, M. Frajblat, L. C. Griel Jr., C. J. Johnson, R. A. Milvae, G. M. Niksic, and J. L. Pate.
2002. Relationship of fertility to ovarian follicular waves before breeding in dairy cows. J. Anim. Sci. 80:1053-1058.

Walsh, S. W., E. J. Williams, and A. C. O. Evans. 2011. A review of the causes of poor fertility in high milk producing dairy cows. Anim. Reprod. Sci. 123:127-138.

Wathes, D. C., M. Fenwick, Z. Cheng, N. Bourne, S. Llewellyn, D. G. Morris, D. Kenny, J. Murphy, and R. Fitzpatrick. 2007. Influence of negative energy balance on cyclicity and fertility in the high producing dairy cow. Theriogenology 68:S232-S241.

Werner, G., L. Casida, and I. Rupel. 1938. Estrus, ovulation, and artificial insemination in cattle. J. Anim. Sci. 1938:54-57.

Wolfenson, D., G. Inbar, Z. Roth, M. Kaim, A. Bloch, and R. BrawTal. 2004. Follicular dynamics and concentrations of steroids and gonadotropins in lactating cows and nulliparous heifers. Theriogenology 62:1042-1055. 